Orbis Tertius, vol. XXV, $\mathrm{n}^{\circ}$ 32, e174, noviembre 2020-abril 2021. ISSN 1851-7811

Universidad Nacional de La Plata

Facultad de Humanidades y Ciencias de la Educación

Centro de Estudios de Teoría y Crítica Literaria

\title{
Sangre de amor correspondido: a small secret war
}

\section{Blood of Requited Love: a small secret war}

\section{Delfina Cabrera * \\ delfina.cabrera@ici-berlin.org \\ ICI Berlin Institute for Cultural Inquiry, Alemania}

Cita sugerida: Cabrera, D. (2020). Sangre de amor correspondido: a small secret war. Orbis Tertius, 25(30), e174. https://doi.org/10.24215/18517811e174
Resumen: Por su rareza, Sangre de amor correspondido se distingue de las otras siete novelas que publicó Manuel Puig. No sólo porque fue compuesta a partir de la grabación, transcripción y traducción de entrevistas que mantuvo en portugués con un albañil brasilero, sino, y en particular, por los interrogantes que plantea con respecto a la autoría, la economía política del sexo, la sexualidad y la lengua. Esta condensación de elementos le otorga una singularidad que puede funcionar como punto de referencia para estudiar otros textos de la época, la de 1980, mientras aún perduraba en América Latina la creencia en el poder emancipador que le asignaba a la literatura su supuesta autonomía.

Palabras clave: Manuel Puig, Sangre de amor correspondido, Traducción, Contrato.

\begin{abstract}
The strangeness of Blood of Requited Love marks it out from Manuel Puig's other seven novels, not only because it was composed on the basis of the recording, transcription and translation of interviews that he held in newly learned Portuguese, but, in particular, because of the questions it raises regarding authorship, the political economy of sex, sexuality and the national language. This condensation of elements gives it a singularity that can function as a point of reference for studying other texts of the period, that of the 1980s, while the belief in the emancipatory power that assigned literature its supposed autonomy still lingered in Latin American letters.
\end{abstract}

Keywords: Manuel Puig, Blood of Requited Love, Translation, Contract.

\section{El PRECIO DE LA GLORIA}

Sangre de amor correspondido es el libro menos comentado de Manuel Puig y ante el éxito de Boquitas pintadas o El beso de la mujer araña fue, sin dudas, un worst-seller. También es su libro más extraño. La ética de la escritura que propone y la lengua de fantasía con la que está hecho (en su sentido más lato: una lengua fuera de la realidad), lo convierten en un texto único que deja en suspenso las leyes (morales, literarias, sexuales) de un orden de cosas que, cuarenta años después, sigue siendo actual. 
La historia es conocida: a comienzos de la década del ochenta, apenas instalado en Río de Janeiro, Puig contrata a un albañil para hacer reformas en su departamento:

Yo le oí hablar, y me pareció que, en el fondo, ese hombre tan distinto y yo teníamos todo en común. Él también era alguien que no podía aceptar la realidad en que estaba metido, y, en su afán de evadirse de ella, la modificaba ante todo con el lenguaje. Siempre había alguna elaboración musical o pictórica en lo que decía. Era un artista (...). Este hombre era un poeta, y de lo que decía se desprendía una poesía campesina que me pareció... - Manuel Puig duda con la palabra, hace un gesto con una mano bastante convincente y da con ella- necesario trasplantarlo a la página (Romero, 2006, p. 208).

En ese trasplante, que es un desarraigo y un arraigo de la voz a la página, está condensada la novela. Primero a cambio de horas extras, luego por un porcentaje de los derechos de autor, luego por una suma fija, según acuerdo, Puig se entrevista con el albañil. No es la primera vez que usa como método la escucha de una vida privada y su captura. En 1973, cuando prepara El beso de la mujer araña, anota conversaciones con ex presos políticos de Villa Devoto y en 1975, ya exiliado en México, con un abogado peronista que había sido condenado por el gobierno de Isabel Martínez de Perón. ${ }^{1}$ En 1976, desde Nueva York, llena cuadernos de apuntes mientras habla con un joven sociólogo en decadencia, su vecino del Greenwich Village. Entre 1978 y 1979, la misma forma, vuelta ficción, aparece en sus crónicas neoyorkinas: libreta o grabadora en mano, Puig increpa con igual destreza al encargado de medir la luz, a una mariquita en un bar sadomaso o a un exterminador de cucarachas.

En el principio, ya lo sabemos, fue la voz; pero en Sangre, Puig quiere más (“...mais?, tudo, tudo o que você lembra daquela noite"). ${ }^{2}$ Desde La traición de Rita Hayworth (1968), como reveló temprano Alan Pauls (1986), el arte narrativo de Puig pone en escena la necesidad y el deseo del relato ajeno, así como los modos de la producción, la circulación y el consumo de ese relato. Cualquier información o saber que se trafique (un chisme, un secreto, una confesión) es presa de un pacto que regula y promueve ese pasaje (algo se da a cambio de otra cosa, de determinada manera). Sin embargo la diferencia llega con Maldición eterna a quien lea estas páginas (1980) y Sangre de amor correspondido (1982), cuando Puig "ya no se limita a escribir, alucinatoriamente, el instante de la recepción, la venta y el intercambio económico que da lugar a un texto. Ahora el contrato está en el origen mismo de la producción del texto" (Pauls, 1986, p. 34). Conocemos el método (contrato, entrevista, transcripción, traducción) porque Puig se encargó de contarlo en cada uno de los reportajes que dio en la época y en la solapa de la edición carioca de Sangre, firmada por Bella Josef. ${ }^{3}$ Son detalles que contrastan con lo poco que dijo sobre el armado de su primera novela ("Yo lo que tomé conscientemente de Joyce es esto: hojeé un poco Ulises y vi que era un libro compuesto con técnicas diferentes. Basta. Eso me gustó”). Pero en los ochenta el tiempo se había acelerado, la sociedad del espectáculo arrasaba con la imaginación, los medios ya eran un fin, y del cine, quedaban sólo ruinas. Entonces Puig publica estas dos novelas insólitas en las que además de hacer explícitos los circuitos del deseo, el poder y el dinero en el proceso narrativo, llama la atención sobre la realidad, como en un descuido, ("y me encontré allí con un personaje, con un ser real vecino del Village"; "sí, se trata de un obrero brasileño"), simula su registro en crudo y lo contamina, hasta la última gota.

Como en todo lo que Puig escribe, en Sangre hay una interrogación general por lo económico y en particular por la economía política del $\operatorname{sexo}^{4}$, una intriga que no se resuelve pero que bordea sin tregua la sexualidad y la violencia. En la primera escena, una chica de quince años entra a un hotel:

Ella le dijo que no le iba a entregar nada. Ahí él le dijo que entonces se acababa todo, que no entendía las intenciones de ella. Ahí ella lloró, se largó a llorar a todo pulmón, y él no aflojó ni un tranco, estaba embalado, con copas encima ¿no? En fin, que siguieron camino. Se la montó como loco.

- ¿En el hotel?

Una noche nada más, en aquel hotel (...). (Puig, 1982, p. 14) 
En esa noche empieza la novela y a ella vuelve con variaciones, desvíos, desacuerdos, silencios. Este mecanismo de repetición con diferencia insiste en mostrar que no hay una verdad sobre el sexo, pero sí una pedagogía:

- ¿Me lastimaste y me heriste?

Ella lloraba, lloraba desesperadamente, era la primera noche, ella nunca había sufrido así, nunca la habían operado de nada, y realmente es algo que lastima y hiere. Él vio que salía sangre ¿está claro? sangre en cantidad. Ahí él buscó y vio la trusita de ella sobre la cama, y con eso le secaba la sangre, con la trusita misma. La misma trusa chiquita de la misma marca que usaban todas las del pueblo. Y él le fue secando todo, y limpiándole. Limpiaba y volvía para adentro, todo lo que se podía. Las cosas iban marchando bien, forzando un poco la cuestión, hasta que no entró todo él no dejó de empujar. Hasta que no llegó hasta la bolsa de los huevos no paró. Ahí sí ya paró. Ella temblaba, sentía frío, le decía que estaba sintiendo frío. Él le decía, "Entonces basta ¿te lo saco entonces?”. Y ella que no, que insistiese, que siguiese entrando, cada vez más. Y no hubo más problemas, todo en orden (...). (pp. 21-22)

El orden podría ser uno de terror, o porno, o de melodrama, tres modos de la cultura de masas de los que Puig adopta, por ejemplo, una estructura (temporal, el suspense), un conjunto de efectos para los cuerpos que leen (asco, placer, dolor) y tres fluidos (sangre, semen, lágrimas) sobre los que es posible cartografiar un régimen de gobierno. ${ }^{6}$ La "historia de amor adolescente" entre Josemar y María da Glória parece por momentos un compendio o un manual de vejaciones, flagelos y engaños que por su solo carácter cotidiano y persistente no deberían sorprender a nadie ("La misma trusa chiquita de la misma marca que usaban todas las del pueblo"). La célebre fórmula con la que Hitchcock distribuía en sus rodajes la fascinación por el padecimiento de las mujeres ("torture the women!"), se impone como pista de lectura. Pero falsa, porque Puig está más interesado en descubrir cómo funciona la administración de la violencia que en representarla.

Esta novela ocupa un lugar rezagado en la extensa bibliografía sobre Puig, como si la crítica la evitara o ya no tuviera fuerzas para detenerse ahí, como si se hubiera agotado después de la intemperie de Maldición eterna y buscara refugio en Cae la noche tropical. Cansancio, desconcierto, tedio: Sangre, además de recursiva y alucinada, es una novela morosa que pone la espera como condición de lectura. Si ya era evidente que al traducir el cine a la literatura Puig había generado un espacio temporal distinto al del espectador, aquí llega a la clave del suspense: la demora de lo que no vendrá. Como en cualquiera de sus textos, la inmediatez no existe: captura, transcripción, traducción, reescritura; nada más lejos de la presentación directa de una cinta grabada, de un testimonio o de una historia de vida. En un tiempo que comienza a registrarlo todo y a producir contenidos en serie, Puig se dedica a explorar los límites de la tecnología (del yo, del género, de la reproducción, de la representación) y dice: no hay escritura inocente; ni gratuita.

Por eso el escándalo: ¿ cómo podía obviarse que Puig no sólo escribiera sobre los goces de un campesino devenido proletariado (el pueblo más pueblo) sino que además lo contratara para escribir? El albañil brasilero no es un personaje a sueldo: vende su palabra a destajo en lugar de entregarla por una buena causa, ya sea una obra de arte, una tesis doctoral o el noticiero de la tarde. Esta provocación y no las acusaciones de procacidad fue lo que desplazó la novela hacia los márgenes de la industria literaria. Aunque "procaz" sea un adjetivo que le corresponda, tal como descubre un comentador anónimo que apenas publicado el libro tampoco se equivoca al anunciar que "sobre la última novela de Manuel Puig se cierne, de nuevo, la sombra de Pasolini" ${ }^{7}$

\section{ÉTICA VAMP}

¿Un repaso por los manuscritos basta para entender que el trabajo de composición fue complejo (apuntes para las entrevistas, esquemas con las cintas numeradas, cientos de correcciones, al menos tres versiones diferentes, etc.); o sea: una técnica precisa, orden, pequeña melodía. En uno de esos borradores, Puig transcribe a máquina la conversación en portugués con el albañil (él mismo, porque las demás transcripciones, hechas por encargo, no tienen errores de ortografía) y no distingue entre las voces. 
Orbis Tertius, vol. XXV, nº 32, e174, noviembre 2020-abril 2021. ISSN 1851-7811

FIGURA 1

SF AT CMPRITNDIMENTOS CULTURAIS E AMTISTICOS ITDA.

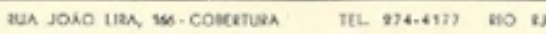

Hä

Cuele fui a ultins vos? dos anos stras, oito anos atrasf. Wao viu nis? no vi nais.

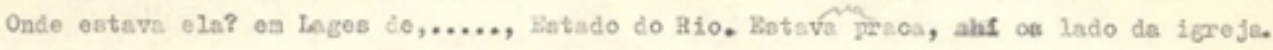
Kals poisas? ahl dali sainos, els vis so beu onoontro, tinahnos encontro maroado. Ahs

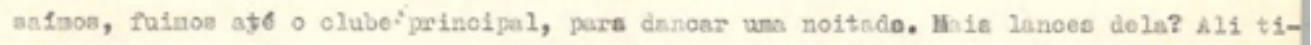

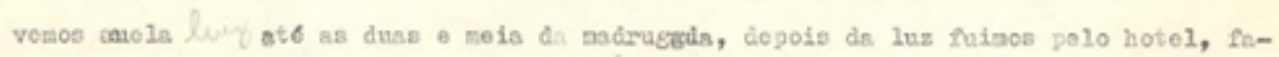

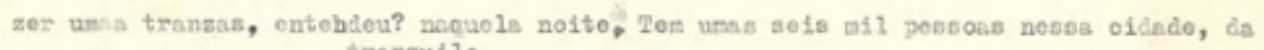
trenguilo, pors ir muit hotel? ds,/ano nao reconheolan els? un hotel noutrs oidsde vizinha, engendeu? af cheganos la, tomanos un chopecinho, de carro? de onrro, de oarro, fuinoe de car

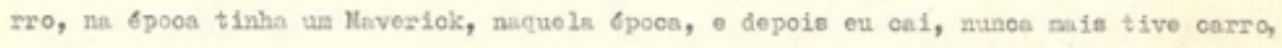
entendou? agors no ano que ves oou couprar un finanoisdo, so Deus Quizerv 0 bailo ors con musice de Roberto Carlos. Todo o tempo a musice ere de Roborto Carlos, s noite tode, doscos, entendeu? llas ceposi delf... teve outros lugares pers a cente ir, a pisceina, o rbo, tocar banho, cachooira, a gente salir naquelas pedres, cachoeira bonita, oheis de pdraf, entao a gonte ooloceva o bikini, un xhort de pania e a gente is toms banho,

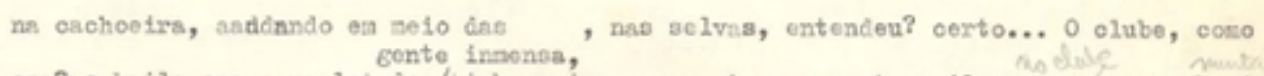
ern? o baile ers superlotado,/tinhs mis o nonos tres o quntro mil possoes, o oonheois

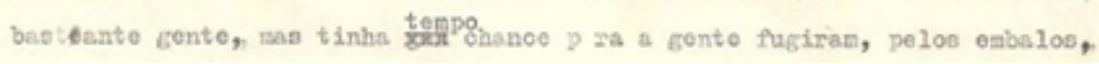

(SAC, ID puig.NSac.N.G.63.0737)

Pero en notas posteriores decide separarlas, introducir un contrapunto y alternar dos personas gramaticales que serán la primera y la tercera en la versión final. En el manuscrito leemos:

FIGURA 2

"Cial fuela últur ves

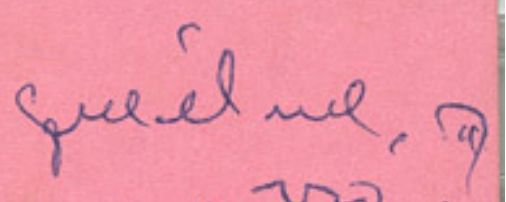

¿Cuauso

she

Ella vio fur ultu

él jer

ilturas?

Contrapunto entre elles

( $S A C$, ID puig.NSac.N.G.19.0242R)

4 
En la versión édita se efectúa el contrapunto:

- ¿Cuál fue la última vez que me viste?

Él la vio por última vez hace diez años, ocho años. Después nunca más. Fue en Cocotá, Estado de Río. En la plaza, del lado de la iglesia ¿verdad? (Puig, 1982, p. 9).

La raya, sola y anónima, no es un parlamento sino una incisión; el corte por donde Puig toma ("de los propios labios del ser real”) un ritmo, un tono, el exceso en la palabra. Es una intervención deliberada que muestra la distancia entre la cinta y las voces, así como la imposibilidad de un discurso directo puro. La falta de sincronía suena como un doblaje mal hecho (de novela) que trae, otra vez, un desacople y la misma pregunta: “quién habla?” ${ }^{8}$. De nuevo, un modo indirecto de narrar, marca registrada de Puig, y un narrador que abandona el poder y cierra los ojos (“vocêtem um olhar assim morto, sabe?”, le dice el albañil). En Sangre, la lengua se tapiza de piel: cuando la mirada única se apaga, un orificio se erotiza: el oído.

"Sabe que, chefãozinho, deixa um pouco também a fantasia correr", "vamos falar um pouquinho de coisas fantásticas", "vou pedir a você um pouquinho de fantasia". ${ }^{10}$ El obrero hace de autor (un poco), y Puig (que también paga para eso), de personaje: "eu gostaria de escutar as palavras que você dizia a ela, especialmente pra dar ilusão. Mas tem que fazer como se ela estivesse aqui. Vocêfala pra ela como naquele momento". ${ }^{11}$ Como todo buen vampiro, además de alimentarse, Puig seduce y contagia; la fantasía que recibe se vuelve inseparable de sus pedidos al chefãozinho, de las escenas que propone y en las que participa. ${ }^{12}$ Es el cruce de experiencias en el marco del contrato y no la simple extracción de plusvalía literaria lo que crea el texto; el tráfico, la circulación, lo que se inventa sólo con otros (son, en verdad, al menos dos los albañiles entrevistados: en el lado B del casete que se conserva hay una tercera voz).

Si bien, como subraya María Moreno, Puig "se detuvo en el momento de pasar el grabador, en el sentido de jaquear la autoría especializada” (2010), con esta novela logra exhibir el problema ético y político del uso de los cuerpos y voces abyectos en la literatura, así como el goce que ese uso lleva impreso. Años antes, hacia fines de los sesenta, la vanguardia artística argentina le había otorgado a este mismo problema un lugar protagónico en el Di Tella con intervenciones ya míticas como Para inducir al espiritu de la imagen (1966) de Oscar Masotta, o La familia obrera (1968) de Oscar Bony. ${ }^{13}$ Pero el experimento de Puig es diferente: no paga para exponer al Otro a un público tan comprometido como voraz (el "sadismo social explicitado", en términos de Masotta), ni para denunciar el modo de producción injusto y cruel del cual también depende el arte, ni para mostrar, al decir de Marx, la mancha de sangre que lleva el dinero en cada mejilla. Descubre que las críticas a la estructura clásica de los que mandan y los que obedecen son casi siempre sordas (los subalternos pueden hablar pero nadie escucha). Sangre de amor correspondido, incluso más que Maldición eterna a quien lea estas páginas, desordena el esquema fijo de los papeles del habla, lleva al extremo la denuncia de Larry en la biblioteca de Nueva York: "De todos modos, ¿a quién mierda le va a interesar lo que hablemos nosotros?" (Puig, [1980] 2000, p. 53) y se concentra tanto en la violencia de la representación y las disputas en torno a la propiedad de las voces como en el orden jerárquico que las sostiene. De ahí que el contrato sea central para la novela; en la fórmula de Pauls: "su matriz generadora, su condición de posibilidad a la vez que su método de escritura, su razón de ser y su principio" (1986, p. 34). Es la figura que vela lo que cifra: la mentira del intercambio libre entre iguales, un modo de producción injusto y cruel; y a su vez, la prueba que permite revelarlo. Al exhibir el contrato, Puig muestra que el ejercicio del poder no es un tema sino un trabajo crítico sobre sí mismo que necesita armarse de estrategias para crear relaciones, singularidades y mundos en común: "La literatura nunca fue para Puig un programa estético (una máquina de hacer novelas)", subraya Daniel Link, "sino, sobre todo, un dispositivo ético: la manera de analizar (postular, rechazar) formas de vida y formas de vivir juntos" (2009). 
Si para la década del ochenta ya era evidente que el arte de la voz en la literatura latinoamericana se había acercado más a una didáctica de la prosopopeya que a una escucha sensible, Sangre de amor correspondido termina de aniquilar el programa de las décadas anteriores ("ser la voz de los que no tienen voz") haciendo de las voces la materia misma de una lengua sin modelo y sin fijeza (en esta novela ni siquiera queda el soporte de los informes policiales de El beso de la mujer araña, ni de las solicitudes de empleo o las cartas de Maldición eterna a quien lea estas páginas). La ética vamp de Puig lo compromete en la práctica con las voces que desea (por eso no las representa) y su escritura nos confronta a la obediencia que elegimos: "Si los críticos reconocen solamente la autoridad incontestada del director”, pregunta en "Una actriz y sus directores”, “¿es que entonces no pueden identificarse más que con el poder establecido?” (1993, p. 115).

\section{A SMALL SECRET WAR}

La escritura de la traducción que está en la génesis del texto enloquece la sintaxis del portugués y el español y rompe con el tiempo acumulativo de la novela. La operación en la lengua se articula con la estructura narrativa; no hay progresión sino demora, un trabajo con lo que interrumpe y la composición de un ritmo: "Dormía, se despertaba, se volvía a dormir, otra vez se despertaba, pensaba, eso que pasa a veces ¿verdad? en terminar esas mierdas de obras en construcción ya empezadas, y quedarse un poco más tranquilo ¿no? tener más tiempo para otras cosas, ese tipo de cosas” (p. 46). Pero la obra nunca se termina y es casi imposible recordar dónde dejamos de leer, qué pasó, cuándo. En contraste con Maldición eterna, que está separada en bloques sin numerar, Sangre mantiene una estructura en dos partes de seis capítulos y un epílogo. Una estructura controlada que se mantiene en tensión con una cronología y una lengua fuera de serie.

"Este lenguaje no podía corresponder a ningún modelo", dijo Puig al presentar Sangre de amor correspondido (Romero, 2006, p. 334), y antes, en una carta familiar: "la novela nueva con problemas pero tiene partes que son lo mejor que he escrito en mi vida, ese albañil fue un genio" (Puig, 2005, p. 312). Si algo falla, no es otra cosa que la continuidad con los lenguajes que codifican el deseo y los cuerpos en posiciones fijas ("entonces era que llegaban esos troncos de lengua hasta la garganta, que eran de no poderse creer", Puig, 1982, p. 105). En cualquier línea del texto hay algo que obstruye, suspende o desvía el sentido; la lectura se detiene en una lengua sin modelo que se resiste a encontrar equivalencias en un orden que somete la fantasía al marco de la norma.

En 1982, Puig había alcanzado el reconocimiento crítico en Brasil. Pero con los "grupos de liberación gay", como él los llama, el desencuentro era cada vez mayor. Denostaron la puesta teatral de El beso de la mujer araña porque Molina no era el homosexual heroico que esperaban y presionaron a Puig para que anunciara su salida del closet. Ante la negativa, se produjo una "small secret war" de la que también forma parte Sangre de amor correspondido. ${ }^{14}$

Las batallas de Puig siempre fueron underground: mientras otros ocupaban las primeras planas, da un paso atrás pero no se retira. Cuando todavía estaba en Nueva York, en pleno campo minado por las guerras del sexo, decide escribir sobre la expansión de la industria pornográfica. Desde las salas de cine y las cabinas individuales de las tiendas de revistas, investiga los discursos emergentes sobre la sexualidad y el género. En ese momento, a fines de los setenta, cuando "buena parte de la literatura feminista atribuía la opresión de las mujeres a las representaciones gráficas del sexo, a la prostitución, a la educación sexual, al sadomasoquismo, a la homosexualidad masculina y al transexualismo" (Rubin, 2018 [1989], p. 128), sus crónicas para la revista Bazaar se concentran en los modos de producción y gestión de los placeres. En Sangre es todavía más explícito y despliega los cruces entre la política y el deseo, entre los cuerpos y el capital, en instituciones tan populares como la pornografía o la homosexualidad pero mucho más poderosas: la Iglesia, la familia y el trabajo asalariado. Frente a las presiones por hacer pública su "identidad sexual", Puig responde con un texto que postula un desvío permanente y una suspensión de los papeles asignados: 
R- Aí, falando assim poetamente: eu uma vez sonhei que tava numa festa no céu, aí lá existia muito macaco.

P- Uma festa?

R- No céu. E lá existia muito macaco, tinha macaco à bessa, então o negócio era pura sacanagem entre mulher, macaco e homem, entendeu? (...)

P- Você que fazia no sonho?

R- Eu tava participando desta festa. ${ }^{15}$

\section{REFERENCIAS}

Acosta, F. y Disalvo, L. (2016). Deseo y decepción. Página 12, Suplemento Las12. Recuperado de https://www.pagin a12.com.ar/diario/suplementos/las12/subnotas/10311-974-2016-01-15.html

Aira, C. (1991). El sultán. Revista Paradoxa, 6, 27-29.

Amícola, J. (2000). Manuel Puig y la narración infinita. En E. Drucaroff (dir.), La narración gana la partida, Historia de la literatura argentina, tomo 11. Buenos Aires, Argentina: Emecé.

Barthes, R. (1971). Sade, Fourier, Loyola. Paris, Francia: Seuil.

Barthes, R. (1983). El grano de la voz. Entrevistas 1962-1980. México D. F., México: Siglo XXI.

Cohen, M. (2014). Música prosaica. Buenos Aires, Argentina: Entropía.

Fogwill, R. (2008). Los libros de la guerra. Buenos Aires, Argentina: Mansalva.

Foucault, M. (1970). Sept propos sur le septieme ange. Paris, Francia: Fata Morgana.

Giordano, A. (2001). Manuel Puig. La conversación infinita. Rosario, Argentina: Beatriz Viterbo.

Goldchluk, G. (2011). El diálogo interrumpido: marcas de exilio en los manuscritos mexicanos de Manuel Puig. Santa $\mathrm{Fe}$, Argentina: Ediciones Universidad Nacional del Litoral.

Goldchluk, G. (2012). Escribir la voz del otro: La lengua de la traducción en Maldición eterna a quien lea estas páginas de Manuel Puig. En Actas del I Congreso de la Delegación Argentina de la Asociación de Lingüística y Filología de América Latina (ALFAL) y V Jornadas Internacionales de Filología Hispánica. La Plata, Argentina: UNLP. FAHCE. CTCL. Cátedra de Filología Hispánica. Recuperado de http://www.memoria.fahce.unlp.edu.ar/trab _eventos/ev.3781/ev.3781.pdf

Gragnolati, M. (2017). Differently Queer. Temporality, Aesthetics, and Sexuality in Pier Paolo Pasolini's Petrolio and Elsa Morante's Aracoeli. En C. Holzhey y M. Gragnolati (eds.), De/Constituting Wholes: Towards Partiality Without Parts. Vienna, Austria: Turia + Kant.

Link, D. (2009). Vivir Juntos. Pagina12, Sumplemento Soy. Recuperado de http://www.pagina12.com.ar/diario/sup lementos/soy/1-780-2009-05-29.html.

Link, D. (2015). Suturas: Imágenes, escrituras, vida. Buenos Aires, Argentina: Eterna Cadencia.

Ludmer, J. (1971). Boquitas pintadas, siete recorridos. Actual. Revista de la Universidad de los Andes, (8-9), 11-22.

Moreno, M. (2010). Doble casetera. Página 12, Suplemento Radar. Recuperado de http://www.pagina12.com.ar/dia rio/suplementos/radar/9-6558-2010-10-24.

Novias precoces y procaces (1982). Revista Semana. Recuperado de https://www.semana.com/cultura/articulo/nov ias-precoces-procaces/471-3/

Páez, R. (1998). Manuel Puig. Delpop a la extrañeza. Buenos Aires, Argentina: Almagesto.

Panesi, J. (1983). Manuel Puig: las relaciones peligrosas. Revista iberoamericana, XLIX (125), 903-916.

Pauls, A. (1986). Manuel Puig, La traición de Rita Hayworth. Buenos Aires, Argentina: Hachette.

Pauls, A. (2009). La zona íntima. En S. Iparraguirre et al., La literatura argentina por escritores argentinos: Narradores, poetas y dramaturgos (377-384). Buenos Aires, Argentina: Ediciones Biblioteca Nacional.

Pineau, N. (s/f). Registro del happening Para inducir al espiritu de la imagen de Oscar Masotta. Recuperado de http ://www.vivodito.org.ar/node/148

Preciado, P. B. (2000). Manifiesto contrasexual. Barcelona, España: Anagrama. 
Puig, M. (1982). Sangre de amor correspondido. Buenos Aires, Argentina: Seix Barral.

Puig, M. (1982). Sangue de amor correspondido. Rio de Janeiro, Brasil: Nova Fronteira.

Puig, M. (1985).Loss of a readership. Index of Censorship, 14, (5).

Puig, M. (2000 [1980]). Maldición eterna a quien lea estas páginas. Buenos Aires: Seix Barral.

Puig, M. (1982). Eternal Curse on the Reader of These Pages. Minneapolis, EE.UU. University of Minnesota Press.

Puig, M. (1993). Los ojos de Greta Garbo. Buenos Aires, Argentina: Seix Barral.

Puig, M. (2005). Querida familia: Tomo II. Cartas americanas (1963-1983). Buenos Aires, Argentina: Entropía.

Romero, J. (1999). Manuel Puig: del delito de la escritura al error gay. Revista Iberoamericana, LXV , (187), 305-325.

Romero, J. (2006). Puig por Puig. Imágenes de un escritor. Madrid, España: Iberoamericana- Vervuert.

Rubin, G. (1975). The Traffic in Women: Notes on the 'Political Economy' of Sex. En R. Reiter (ed.), Toward an Anthropology of Women. New York, EE.UU.: Monthly Review Press.

Rubin, G. (2018). En el crepúsculo del brillo. La teoría como justicia erótica. Córdoba, Argentina: Bocavulvaria.

Speranza, G. (2006). Fuera de campo. Literatura y arte argentinos después de Duchamp. Barcelona, España: Anagrama.

Spoto, D. (1983). The Dark Side of Genius. The Life of Alfred Hitchcock. Boston, EE.UU.: Little, Brown.

Williams, L. (1989). Hard Core: Power, Pleasure, and the Frenzy of the Visible. California, EE.UU.: University of California Press.

Williams, L. (1991). Film Bodies: Gender, Genre, and Excess. Film Quarterly, 44, (4), 2-13.

\section{Notas}

1 Para un análisis de estas entrevistas en el marco del proceso genético de El beso de la mujer araña y Pubis angelical véase Goldchluk (2011).

2 Salvo indicación contraria, las citas en portugués corresponden a una desgrabación reciente de un fragmento de la entrevista que se conserva en el Archivo Puig. Las transcripciones originales (en las que se omiten algunas interacciones, repeticiones e interrupciones) pueden consultarse en el portal de acceso abierto ARCAS de la Universidad Nacional de La Plata: http://arcas.fahce.unlp.edu.ar/arcas/portada/acerca_de_arcas

3 Muchos de estos reportajes han sido compilados por Julia Romero (2006). En la solapa de la primera edición en português de Sangue de amor correspondido, se lee: "Um pedreiro, contratado para fazer uma obra em sua casa, revelouse ótimo personagem e, gravador em punho, Manuel Puig captou a linguagem metafórica sabrosa e criadora do futuro Josemar (...) Porém, não se trata apenas da reprodução de um gravador: houve uma reelaboração estética, com critério musical e rítmico, em que Manuel Puig tomou o cuidado de não desvirtuar essas vozes, já que ele próprio preparou quase inteiramente a versão portuguesa com amplio sentido da linguagem”.

4 Este concepto es desarrollado en su clássico ensayo por la antropóloga Gayle Rubin (1975).

5 Todas las citas de la versión en español pertenecen a la primera edición de Seix Barral de 1982.

6 Linda Williams (1991) desplaza al melodrama de la categoría genérica y lo postula como un modo de la cultura de masas, además analiza cómo se enlazan el melodrama, el porno y el cine de terror con las tecnologías de visualidad y de producción de subjetividades generizadas.

7 "Sobre Manuel Puig importa definir si sus tres últimas novelas, publicadas una detrás de otra cada año a partir de Pubis angelical caben en lo que podría calificarse de pornográfico, sin interés literario. Habría caído así el aparentemente joven autor argentino en la explotación de un mercado fácil y productivo dejando de lado la verdadera creación para la cual posee amplias facultades. Recordemos un poco su formación como figura de las letras. Empezó en Italia, a donde llegó a los veinte años para estudiar dirección cinematográfica coincidiendo con los que después serían grandes directores: Antonioni, Fellini, Pasolini, que iniciaban entonces su preparación (era 1952) y que debieron influir lógicamente en el argentino, sobre todo el último" (Semana, 26/07/1982).

8 La estética del doblaje es común a Maldición eterna a quien lea estas páginas y a Sangre de amor correspondido, donde abundan, por ejemplo, los calcos sintácticos: “¿Dónde es que él puso los cigarros?” (p. 25); “Él llegó, golpeó las manos en el portón de la casa, en la chacra de la madre, entonces ella dijo, «El asunto es el siguiente: yo tengo un hijo que se llama así, Josemar, pero a usted no lo conozco»” (p. 42); “En ese partido hizo unos cinco goles. Los únicos cinco goles del partido los hizo él. Él estaba con toda la cuerda dada esa tarde. Las hembras vibraban, mucha mujer” (p. 18).

9 “Tenés una mirada así como muerta, ¿sabés?”. 
10 "Sabés qué, jefecito, dejá correr la fantasía un poco también"; "hablemos un poco de cosas fantásticas"; "te voy a pedir un poco de fantasía”.

11 "Me gustaría escuchar las palabras que le decías a ella, especialmente para darle ilusión. Pero tenés que hacer como si ella estuviera acá. Hablarle como en ese momento."

12 Para una lectura de las novelas de Puig (en especial, las del ciclo del exilio) desde las figuras del vampiro y el parásito véase Pauls (2009).

13 En Para inducir al espíritu de la imagen (1966), Oscar Masotta contrata a cuarenta hombres y mujeres mayores vestidos "de pobres" y los ilumina con reflectores en el Instituto Di Tella, bajo un sonido insoportable, agudo y continuo: “contó que los 'viejos' habían sido contratados por medio de algún tipo de agencia de extras teatrales por, en principio, cuatrocientos pesos, y que luego él había decidido pagarles seiscientos; que les estaba pagando para que se dejaran mirar y que el público había pagado doscientos pesos para mirarlos y que de este modo se generaba una circulación de dinero en la que él aparecía como mediador. Tras ello, entonces, vació un matafuego sobre la tarima, prendió los reflectores y encendió el sonido" (Pineau). Dos años después, Oscar Bony hace una instalación performática en la misma línea, La familia obrera, en la que un matricero, su esposa y su hijo son exhibidos sobre una tarima. Bony incluyó un cartel con información sobre el pago que recibía la familia por estar en la sala, pago que correspondía al doble de lo que ganaba el matricero en una jornada laboral.

14 En "Loss of a Readership", un artículo que publica en 1984, se lee: "By 1982 I had become quite well known in Brazil and the militant gay groups were pressuring me to make declarations about my sexual ways, so to announce my official "coming out of the Closet". I felt something wrong about giving an official stamp to my sexuality and preferred to keep my privacy. That produced a small secret war and a new form of censorship was born. In 1982 another play of mine opened in Rio de Janeiro, and the two gay critics reduced the play to ashes" (Romero, 1999, p. 323).

15 "R- Hablando así poetamente; una vez soñé que estaba en una fiesta en el cielo y que ahí había muchos monos. / PUna fiesta? / R- En el cielo. Y que ahí había muchos monos, monos en cantidad, entonces el asunto era pura joda entre mujeres, monos y hombres, entendés? (...) / P- ¿Vos qué hacías en el sueño? / R- Yo estaba participando de esa fiesta” (ID puig.NSac.N.G.7.0112) Cito de mi traducción.

\section{Notas DE AUTOR}

Agradezco especialmente a Graciela Goldchluk, Laura Gutiérrez, Oriana Seccia y Juan Pablo Canala por sus lecturas, sugerencias y comentarios a las distintas versiones de este texto. 